\title{
Nuclear Transcription Factor Kappa B (NF-kB) and Molecular Damage Mechanisms in Acute Cardiovascular Diseases. A Review
}

\author{
Roxana Buzas ${ }^{1}$, Alexandru Florin Rogobete ${ }^{1,2}$, Sonia Elena Popovici ${ }^{1,2}$, Tudor Mateescu ${ }^{1}$, \\ Teodora Hoinoiu ${ }^{1}$, Virgiliu-Bogdan Sorop ${ }^{1}$, Tiberiu Bratu ${ }^{1}$, Marian Ticlea ${ }^{3}$, Calin Marius \\ Popoiu ${ }^{1}$, Dorel Sandesc ${ }^{1,2}$
}

${ }^{1}$ Faculty of Medicine, "Victor Babeș" University of Medicine and Pharmacy, Timișoara, Romania

${ }^{2}$ Clinic of Anaesthesia and Intensive Care, "Pius Brinzeu" Emergency County Hospital, Timișoara, Romania

${ }^{3}$ Faculty of Medicine and Pharmacy, University of Oradea, Oradea, Romania

\begin{abstract}
Worldwide, cardiovascular diseases (CVDs) represent one of the main causes of morbidity and mortality, and acute coronary syndromes are responsible for a large number of sudden cardiac deaths. One of the main challenges that still exist in this area is represented by the early detection and targeted monitoring of the pathophysiology involved in CVDs. During the last couple of years, researchers have highlighted the importance of molecular and epigenetic mechanisms involved in the initiation and augmentation of CVDs, culminating in their most severe form represented by acute myocardial infarction. One of the most studied molecular factors involved in this type of pathology is represented by nuclear transcription factor kappa $\mathrm{B}(\mathrm{NF}-\kappa \mathrm{B})$, as well as the involvement of microRNAs (miRNAs). It has been suggested that miRNAs can also be involved in the complex process of atheromatous plaque vulnerabilization that leads to an acute cardiac event. In this review paper, we describe the most important molecular mechanisms involved in the pathogenesis of CVDs and atheromatous plaque progression and vulnerabilization, which include molecular mechanisms dependent on $\mathrm{NF}-\kappa \mathrm{B}$. For this paper, we used international databases (PubMed and Scopus). The keywords used for the search were "miRNAs biomarkers", "miRNAs in cardiovascular disease", "NF-кB in cardiovascular disease", "molecular mechanism in cardiovascular disease", and "myocardial NF- $-\mathrm{B}$ mechanisms". Numerous molecular reactions that have $\mathrm{NF}-\kappa \mathrm{B}$ as a trigger are involved in the pathogenesis of CVDs. Moreover, miRNAs play an important role in initiating and aggravating certain segments of CVDs. Therefore, miRNAs can be used as biomarkers for early evaluation of CVDs. Furthermore, in the future, miRNAs could be used as a targeted molecular therapy in order to block certain mechanisms responsible for inducing CVDs and leading to acute cardiovascular events.
\end{abstract}

Keywords: miRNAs, cardiovascular diseases, atheromatous plaque, plaque vulnerability

\section{ARTICLE HISTORY}

Received: April 3, 2018

Accepted: May 30, 2018

\section{CORRESPONDENCE}

Alexandru Florin Rogobete

Str. Eftimie Murgu nr. 2

300014 Timișoara, Romania

Tel: +40 256204400

E-mail: alexandru.rogobete@umft.ro

Roxana Buzas: Str. Eftimie Murgu nr. 2, 300014 Timișoara, Romania. Tel: +40 256204 400, E-mail: roxanabuzas@yahoo.com Sonia Elena Popovici: Str. Eftimie Murgu nr. 2, 300014 Timișoara, Romania. Tel: +40 256204 400, E-mail: popovici.sonia@yahoo.com Tudor Mateescu: Str. Eftimie Murgu nr. 2, 300014 Timișoara, Romania. Tel: +40 256204 400, E-mail:tudor_mat@yahoo.ro Teodora Hoinoiu: Str. Eftimie Murgu nr. 2, 300014 Timișoara, Romania. Tel: +40 256204 400, E-mail: tstoichitoiu@umft.ro Virgiliu-Bogdan Sorop: Str. Eftimie Murgu nr. 2, 300014 Timișoara, Romania. Tel: +40 256204 400, E-mail: bogdan.sorop@gmail.com Tiberiu Bratu: Str. Eftimie Murgu nr. 2, 300014 Timișoara, Romania. Tel: +40 256204 400, E-mail: tiberiu.bratu@umft.ro Marian Ticlea: Piața 1 Decembrie nr. 10, 410073 Oradea, Romania. Tel: +40 259408 404, E-mail: marian.ticlea@gmail.com Calin Marius Popoiu: Str. Eftimie Murgu nr. 2, 300014 Timișoara, Romania. Tel: +40 256204 400, E-mail: calin.popoiu@umft.ro Dorel Sandesc: Str. Eftimie Murgu nr. 2, 300014 Timișoara, Romania. Tel: +40 256204 400, E-mail: dsandesc@yahoo.com 


\section{BACKGROUND}

In the last years, worldwide, according to published studies and statistics, a high percentage of patients suffer from cardiovascular diseases (CVDs). According to the World Health Organization, starting with 2005, the number of deaths caused by CVDs has reached 17.5 million, compared to only 14.4 million registered in 1991. Furthermore, the WHO has estimated a number of 20 million deaths caused by CVDs for the year 2015. CVDs include a wide range of pathologies, such as ischemic heart disease, stroke, congestive heart failure, coronary heart disease, and rheumatic heart disease, most of them manifesting as various types of cardiovascular emergencies. ${ }^{1-4}$

If we were to talk about the most common pathology involved in the development and augmentation of CVDs, the pro-inflammatory component stands in the first line. ${ }^{5}$ It is well known that in certain situations, inflammation can be beneficial for defense and tissue-remodeling mechanisms. However, when the inflammation becomes overexpressed or chronic, it is responsible of inducing certain pathological phenomena at myocardial level. Among these phenomena, the most commonly mentioned are ischemia-reperfusion syndrome (IR), myocardial infarction, atherosclerosis, aortic valve disorder, and heart failure. ${ }^{6-9}$ Therefore, the role of inflammation in triggering an acute cardiac condition is currently well established.

One of the main pathologies developed at cardiovascular level is represented by atherosclerosis, which eventually can be defined as a molecular and cellular inflammation complex. ${ }^{10-13}$ of course, if we were to look at a molecular and cellular level, the vascular endothelium is the main involved cofactor. From a molecular viewpoint, the key player is represented by nuclear transcription factor kappa $\mathrm{B}(\mathrm{NF}-\mathrm{kB})$, which, according to recent studies, is responsible for the modulation of molecular and epigenetic signals at this level..$^{14,15}$

In this paper, we aim to present the most complex molecular mechanisms involved in the development and augmentation of CVDs and especially their most severe forms of manifestation, represented by acute cardiovascular events. Moreover, we wish to highlight a series of biomarkers that could be used in the early diagnosis and monitoring of CVDs.

\section{THE MOST COMMON MOLECULAR MECHANISMS INVOLVED IN CVDS}

Mitochondrial dysfunctions are relevant factors involved in the augmentation of cardiovascular diseases and pro- gression to an acute or critical stage. Numerous species of microRNAs are involved in the pathogenesis of mitochondrial damage, these being responsible for the excess production of oxygen free radicals (OFRs), as well as for endothelial and vascular dysfunctions. ${ }^{16-23}$ Magenta et al. have investigated the effects and implications of OFRs on the epigenetic mechanisms of miRNAs. ${ }^{24}$ Oxidative stress (OS), as well as increased production of OFRs have important implications in the pathogenesis of CVDs through the ischemia and ischemia-reperfusion (IR) syndrome injury they can cause. ${ }^{18,21,22}$ Furthermore, from a molecular point of view, another important factor is represented by hydrogen peroxide $\left(\mathrm{H}_{2} \mathrm{O}_{2}\right)$ and superoxide anion, both responsible for inhibiting cell growth and inducing cell death and senescence. ${ }^{23}$ Following their study, they have shown that aberrant expressions of miRNA-200c induce growth arrest, apoptosis, and senescence in human umbilical vein endothelial cells. ${ }^{24}$

Although there are plenty of studies regarding the molecular mechanisms responsible for cell death, the epigenetic implications still remain obscure. Recently, it was reported that the $\mathrm{p} 66^{\text {ShcA }}$ protein is involved by modifying certain mechanisms responsible for ischemia-induced cell death. From a biochemical point of view, the p $66^{\text {ShcA }}$ protein represents an $\mathrm{N}$-terminal domain, being phosphorylated to threonine as a response to the attack of $\mathrm{H}_{2} \mathrm{O}_{2}$. Zaccagnini et al. have studied the changes involved in the ischemia/reperfusion-induced cell death by suppressing p66 $6^{\text {ShcA }}$ during the redox attack. They have shown that p6 $6{ }^{\text {ShcA }}$ plays an important role in cell death pathways by blocking and decreasing cell death. Moreover, in this study they called into question using $\mathrm{p} 66^{\text {ShcA }}$ as a future therapeutic target for the prevention of ischemic tissue damage. 25

Lin et al. have investigated the molecular mechanisms and the relations with miRNAs in the case of $\mathrm{H}_{2} \mathrm{O}_{2}$ redox attacks on vascular smooth muscle cells (VSMCs). They have shown that miRNA-21 is responsible for augmented cell death in the case of specific molecular mechanisms through redox activation. ${ }^{26}$

Another study shows the significant implications of vascular adhesion molecule-1 (VCAM-1) and intercellular adhesion molecule-1 (ICAM-1) in the pathogenesis of atherosclerosis. They have proven that VCAM-1 plays an important role in initiating atherosclerosis. ${ }^{27}$ It is also well known that such intercellular adhesion molecules play a significant role in the complex process of coronary plaque vulnerabilization and the development of sudden coronary artery occlusion, thus leading to acute myocardial infarction. Recent studies have shown important implica- 
tions of the receptor-activator of nuclear factor kappa B ligand - receptor-activator of nuclear factor kappa B osteoprotegerin (RANKL-RANK-OPG) in the development of myocardial muscle in the embryonic phase, in muscle remodeling during a myocardial infarction, and in modulating cytokine activity in the immune-inflammatory segment of cardiac pathogenesis. Following this study, Lu et al. have concluded that by activating the RANKL-RANKOPG system, the balance of pro- and anti-inflammatory cytokines is significantly affected, leading to alterations in the cardiovascular function. ${ }^{28}$

Another important factor in the pathogenesis of atherosclerosis is represented by peroxisome proliferatoractivator receptors (PPARs). Bendaya et al. have shown a series of mechanisms involved in the pathogenesis of atherosclerosis through the modulation of fatty acid translocase CD36 activity in peripheral blood mononuclear cells. ${ }^{29}$

\section{EPIGENETIC EXPRESSION IN CVDS}

Recent studies have shown that noncoding (nc) RNA is responsible for most of the genetic regulation mechanisms. ${ }^{30,31}$ Regarding its mechanism of action, ncRNAs are associated with chromatin and transcriptional activation responsible for the post-transcriptional control of the involved genes. Together with the identification of aberrant expressions of genes responsible for the control of a certain pathogenic mechanism, certain answers have been given regarding the genetic links and genetic mechanisms involved in altering cardiovascular functions. ncRNAs form a large family, comprising of ribosomal RNAs (rRNAs), small nucleolar RNAs (snoRNAs), transfer RNAs (tRNAs), and small nuclear RNAs (snRNAs). ${ }^{32,33}$ Moreover, ncRNAs can be divided depending on their main mechanisms of action. ${ }^{34-39}$ Among these, we mention the transcriptional regulation, especially represented by the modulation of GAS5, MALAT1, and NEAT1 genes; through post-transcriptional regulation or epigenetic regulation ncRNAs are involved in the chromatin-remodeling for XIST and HOTAIR genes.

miRNAs have a higher specificity when it comes to molecular mechanisms responsible for cardiovascular changes. A recent study published by Zhang et al. reported 65 miRNAs involved in pathological modifications at cardiovascular level. ${ }^{40}$

From a biochemical point of view, miRNAs are noncoding, single-stranded RNA species comprising of approximately 17-24 nucleotides. ${ }^{33}$ The synthesis processes of miRNAs take place in the nucleus, through the action of RNA polymerase II on specific genes. ${ }^{41,42}$ Following this nuclear reaction, the first epigenetic miRNA species are obtained, called pri-miRNAs. In the next step, RNA polymerase III, also called Drosha complex, will attack the primiRNAs, leading to the formation of pre-miRNAs. This reaction takes place only if it is catalyzed by the DiGeorge Syndrome Critical Region 8 (DGCR8). ${ }^{43-46}$ The transporting protein, Exportin 5, will then act on the pre-miRNAs, which will transfer the epigenetic complex from the nucleus to the cell cytoplasm. ${ }^{47-49}$ Once the signal that the complex has reached the cytoplasm is received, RNA polymerase III (Dicer) and trans-activator RNA binding protein (TRBP) attack it and lead to the formation of mature miRNAs. ${ }^{5,50}$ This molecular species is then introduced in the RNA-induced silencing complex (RISC) and released in the cell under various forms. The most common forms are microvesicles, apoptotic bodies, exosomes, and highdensity lipoproteins. ${ }^{22}$

Furthermore, regarding the action mechanisms, researchers came to the conclusion that miRNAs are involved in inflammation, in the redox response, nutrient sensing, and silent mating-type information regulation 2 homolog (SIRT1)-regulated events. ${ }^{44,51}$

They have also proven that by stimulating miRNA-21, certain proteins that augment the cellular injury are stimulated, among which the most significant is programmed cell death 4 (PDCD4). Olivieri et al. have studied a series of microRNA expressions in the case of vascular cell senescence..$^{52}$ Following their study, they have reported an overexpression for miRNA-146a, miRNA-9, miRNA-204, and miRNA-367 in vascular cell injury. ${ }^{52}$

Ucar et al. have also shown significant implications of the overexpression of the miRNA-212/132 family in cardiovascular diseases. The molecular mechanisms they studied were related to the activity of the $\mathrm{FoxO}_{3}$ transcription factor; they have also shown that the overexpression of miRNA-212/132 leads to an overstimulation of pro-hypertrophic NFAT signaling. Last but not least, it was proven that by inhibiting the activity of miRNA-132 with antagonizing injections, one can considerably reduce cardiac hypertrophy in animal experiments. ${ }^{53}$

\section{miRNAS AND ACUTE MYOCARDIAL INFARCTION}

In a similar study, Long et al. have proven significant links between aberrant expressions of miRNA-1 and miRNA-126 and acute myocardial infarction. ${ }^{54}$

Another study has shown significant implications for miRNA-30a, miRNA-195, and let-7b in acute myocardial infarction. Numerous other studies have also reported ab- 


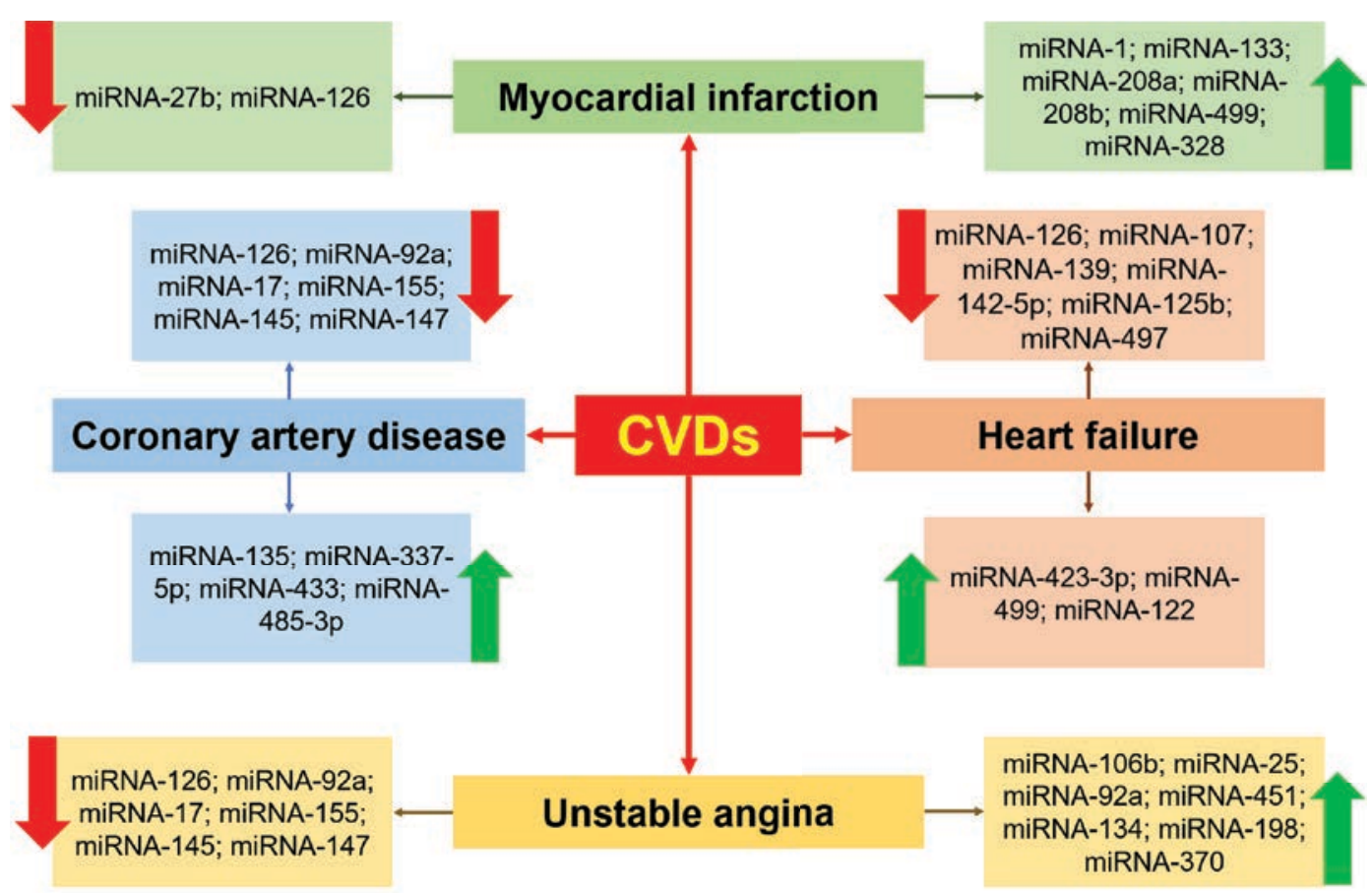

FIGURE 1. miRNA expression in the most common cardiovascular diseases (CVDs). ${ }^{56,58-66}$

errant changes in the expression of miRNA-1, miRNA-133, miRNA-208a/b, miRNA-499, miRNA-318, and miRNA-126 in the case of acute myocardial infarction. ${ }^{55}$

Regarding the expression of miRNAs in CVDs, Fichtlscherer et al. have shown significant changes in the endothelium for miRNA-126, miRNA-17, miRNA-20a, miRNA-92a, miRNA-221, miRNA-21, miRNA-199a-5p, miRNA-27a, miRNA-130a, and let-7d. ${ }^{56}$ A number of studies speak about the implications of miRNAs in different molecular and pathogenic mechanisms such as cholesterol metabolism, where changes in the expressions of miRNA-103, miRNA-26, miRNA-30c, miRNA27a, miRNA-27b, miRNA-106b, and miRNA-144 have been reported. Recent research in smooth muscle differentiation demonstrated changes in the expressions of miRNA-1, miRNA-21, miRNA-26a, miRNA-29b, miRNA125b, miRNA-126, miRNA-132, miRNA-133a, miRNA-133, miRNA-143, miRNA-145, miRNA-208, miRNA-638, miRNA-663, and let-7d. ${ }^{57}$

Figure 1 shows the most important changes in miRNA expression in the most common cardiovascular diseases. ${ }^{56,58-66}$

\section{NF $-\kappa B$, INFLAMMATION, AND ATHEROSCLEROSIS}

Another important factor involved in the molecular mechanisms that lay at the basis of cardiovascular dis- eases is represented by nuclear factor kappa $\mathrm{B}(\mathrm{NF}-\kappa \mathrm{B}) .^{15}$ Regarding its mechanism of action, $\mathrm{NF}-\kappa \mathrm{B}$ is responsible of the regulation of pro-inflammatory cytokines and their modulation inside the cardiac tissue, especially during IR injury. From a structural viewpoint, NF- $\kappa \mathrm{Bs}$ are proteins containing approximately 300 amino acids, also called RELSIH (Rel). These comprise of heterodimers and ho-

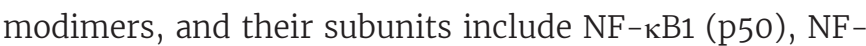
кB2 (p52, p49 and p50B), p65 (RelA), and cRel. A series of inhibitors are involved in the inhibition reactions of NF$\kappa \mathrm{B}$, among which the most important ones are represent-

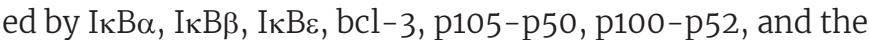
IкB $\gamma-$ p105 gene. ${ }^{15,67-70}$ From a pathological point of view, $\mathrm{NF}-\kappa \mathrm{B}$ is involved in the modulation of certain genes responsible for the further modulation of the pro-inflammatory activity and of the immune response. The most common activation reactions of $\mathrm{NF}-\kappa \mathrm{B}$ are represented by phosphorylation and activation of IкB kinase complex.

In a study on $\mathrm{NF}-\kappa \mathrm{B}$ involvement in the development of atherosclerosis, Hajra et al. have shown that the components of $\mathrm{NF}-\kappa \mathrm{B} / \mathrm{I} \kappa \mathrm{B}$ are most likely responsible for the pathogenesis of CVDs by initiating and augmenting the atherosclerotic process. ${ }^{71}$ Kanters et al. have also shown a significant decrease in the expression of interleukin 10 (IL-10) pro-inflammatory cytokine after the inhibition of $\mathrm{NF}-\kappa \mathrm{B}$. Following their study, they have reported that inactivating $\mathrm{NF}-\kappa \mathrm{B}$ will affect the balance between proinflammatory and anti-inflammatory mechanisms. ${ }^{72}$ 


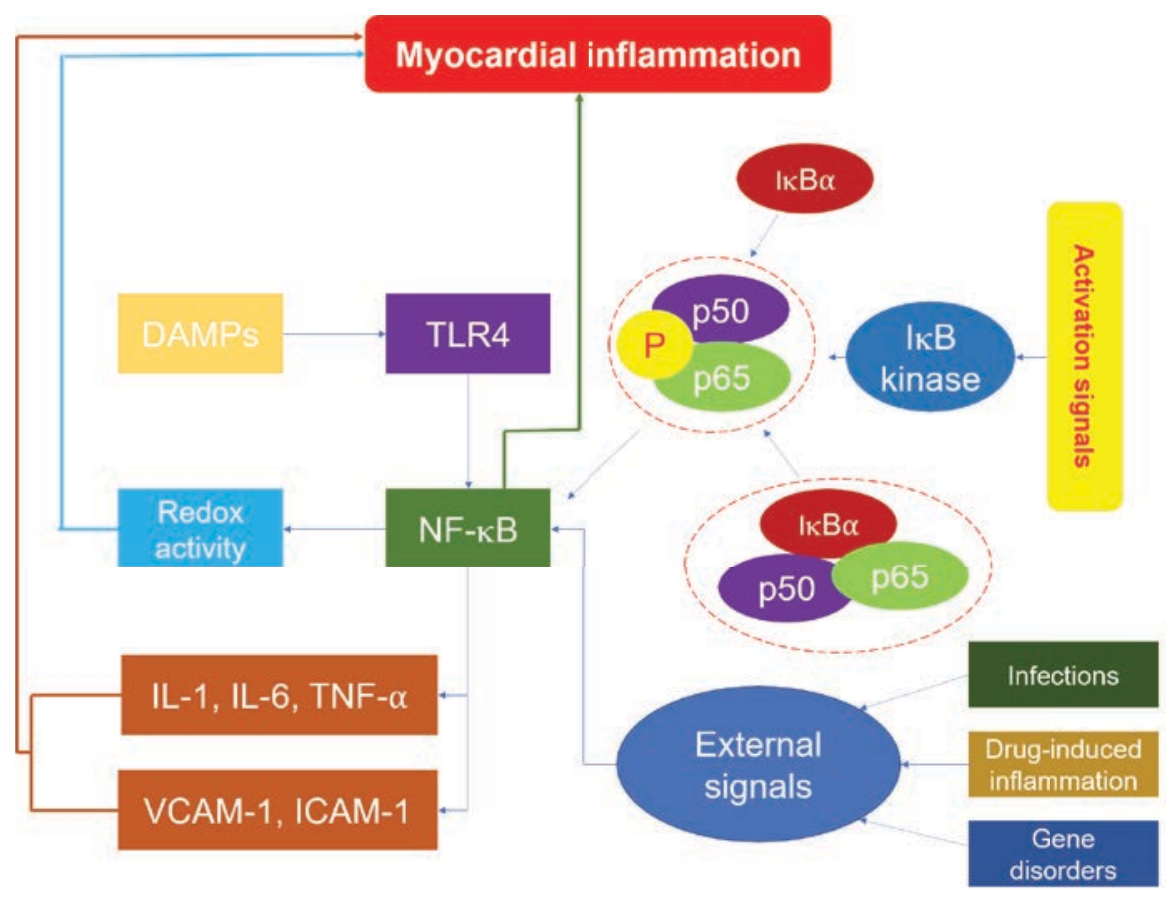

FIGURE 2. $N F-\kappa B$ implications in myocardial inflammation, induced by TLR4. For details please see text.

Moreover, numerous studies demonstrated that the activity of $\mathrm{NF}-\kappa \mathrm{B}$ has important implications on the hemodynamic status, cytokine activity, matrix signaling, angiotensin II activity, advanced glycation mechanisms, and adhesion molecules such as VCAM-1 and ICAM-1. Recent studies have reported a series of implications of NF$\kappa \mathrm{B}$ in the formation of the atherosclerotic plaque through mechanisms that include the expression of a dominantnegative IкB $\alpha$ suppressor ( $\mathrm{DNI} \mathrm{K} \mathrm{B} \alpha$ ). Gareus et al. have studied the mechanisms of $\mathrm{NF}-\kappa \mathrm{B}$ involved in the genesis of atherosclerosis. ${ }^{14}$ Following this study, they have shown that $\mathrm{NF}-\kappa \mathrm{B}$ is involved in the endothelial pro-inflammatory response and activates the pathogenesis of atherosclerosis. ${ }^{14}$

Recently, it was reported that oxidized LDL (oxLDL) presents a series of implications in the development of CVDs by activating endothelial receptors. Changes at the level of vascular endothelium are possible because of the activation of $\mathrm{NF}-\kappa \mathrm{B}$, which further modulates the proinflammatory molecular activity through the activation of E-selectin, VCAM-1, and ICAM-1. Following their study, Yurdagul et al. proved that oxLDL are responsi-

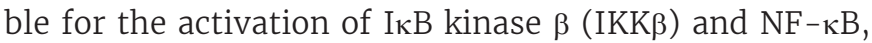
which then lead to an overexpression in pro-inflammatory genes. ${ }^{73}$

Another important role in the pathogenesis of CVDs is played by dendritic cells (DCs), which represent the pathological liaison between the innate and adaptive im- mune systems. The maturation of CDs includes a number of different steps, among which the most important ones are the high cell surface expression of $\mathrm{CD}$-stimulatory cytokines (CD40, CD86, and $\mathrm{CD}-80$ ) responsible for the augmentation of certain processes such as tumor necrosis factor alpha (TNF- $\alpha$ ), interleukin 10 (IL-10), interleukin 12 (IL-12), and type I interferon (IFN- $\gamma$ ). Obviously, NF- $\mathrm{kB}$ is involved in all these biochemical and epigenetic reactions by triggering the activation and transcription of the genes involved. ${ }^{74}$

Meng et al. have studied the implications of $\mathrm{NF}-\kappa \mathrm{B}$ in these mechanisms, reporting that angiotensin II is involved in the activation of DCs through the $\mathrm{p} 65 / \mathrm{NF}-\kappa \mathrm{B}$ system. ${ }^{74}$

Regarding the molecular mechanisms responsible for myocardial inflammation, the most widely discussed are pattern recognition receptors (PPRs) through the recognition and activation of damage-associated molecular patterns (DAMPs). Apart from PRRs, another molecular line is represented by the Toll-like receptors (TLRs), widely studied in relation with the mechanisms of myocardial inflammation. Regarding the expression of TLRs in the myocardial tissue, numerous studies have reported a significantly higher expression of TLR both in the cardiac myocytes and in the endothelial cells. Among these are the following: TLR-4, TLR-2, TLR-3, TLR-6, TLR-1, TLR-8, TLR-10, and TLR-7. Out of this large family, specialty studies have shown numerous implications of TLR4 
in CVDs. From a molecular point of view, in the activation of TLR4 intervenes the myeloid differentiation factor 81 (MyD88), which is responsible of the connection between Toll/Interleukin-1 (Toll/IL-1) receptor (TIR) and TLR4. As a result, the $\kappa \mathrm{B}$ (IкB) kinase $\alpha$ (IKK $\alpha) / \mathrm{IKK} \beta / \mathrm{IKK} \gamma$ molecular complexes are activated, which are further responsible of IK $\beta$ phosphorylation. The NF- $\mathrm{KB}$ transcription factor will then result from the phosphorylated IK $\beta$. Once the NF- $\mathrm{KB}$ is activated, a series of other reactions will be augmented, molecular reactions responsible for the overexpression of interleukin-6 (IL-6), interleukin-1 (IL-1), and TNF- $\alpha^{6,75,76}$ (Figure 2).

\section{CONCLUSIONS}

A series of pathologies that are both induced and augmented by genetic and molecular mechanisms are involved in the development of CVDs and in the complex physiopathological chain of acute myocardial infarction. The most relevant factors for this process include the proinflammatory status and alteration of the balance between pro-inflammatory and anti-inflammatory factors. This molecular imbalance is induced by the over-expression or inhibition of $\mathrm{NF}-\kappa \mathrm{B}$. Based on current literature, we can conclude that $\mathrm{NF}-\kappa \mathrm{B}$ is involved in most pro- and antiinflammatory processes underlying CVDs. Moreover, by using the expression of certain specific miRNAs, we can prevent certain cardiovascular pathologies, and we can choose the most appropriate therapeutic interventions in order to block molecular damage patterns. However, further research regarding the usage of these epigenetic species in the therapy of CVDs, and especially of acute coronary syndromes, is necessary.

\section{CONFLICT OF INTEREST}

Nothing to declare.

\section{REFERENCES}

1. Mitropoulos FA, Odim J, Marelli D, et al. Outcome of hearts with cold ischemic time greater than 300 minutes. A casematched study. Eur J Cardiothorac Surg. 2005;28:143-148. doi: 10.1016/j.ejcts.2005.01.067.

2. Tonkin AM, Blankenberg S, Kirby A, et al. Biomarkers in stable coronary heart disease, their modulation and cardiovascular risk: The LIPID biomarker study. Int J Cardiol. 2015;201:499507. doi: 10.1016/j.ijcard.2015.07.080.

3. Vella RK, Pullen C, Coulson FR, Fenning AS. Resveratrol Prevents Cardiovascular Complications in the SHR/STZ Rat by Reductions in Oxidative Stress and Inflammation. Biomed Res Int. 2015;2015:918123. doi: 10.1155/2015/918123.
4. Melania L, Alexandru B, Rogobete F, et al. The Use of Redox Expression and Associated Molecular Damage to Evaluate the Inflammatory Response in Critically Ill Patient with Severe Burn. Biochem Genet. 2016;54:753-768. doi: 10.1007/s10528016-9763-8

5. Rogobete AF, Sandesc D, Papurica M, et al. The influence of metabolic imbalances and oxidative stress on the outcome of critically ill polytrauma patients: a review. Burn Trauma. 2017;5:8. doi: 10.1186/s41038-017-0073-0.

6. Yang Y, Lv J, Jiang S, et al. The emerging role of Toll-like receptor 4 in myocardial inflammation. Cell Death Dis. 2016;7:e2234. doi: 10.1038/cddis.2016.140.

7. Weiss JBW, Eisenhardt SU, Stark GB, Bode C, Moser M, Grundmann S. MicroRNAs in ischemia-reperfusion injury. Am J Cardiovasc Dis. 2012;2:237-247.

8. Mansour Z, Charles AL, Kindo M, et al. Remote effects of lower limb ischemia-reperfusion: Impaired lung, unchanged liver, and stimulated kidney oxidative capacities. Biomed Res Int 2014;2014:392390. doi: 10.1155/2014/392390.

9. David VL, Ercisli MF, Rogobete AF, et al. Early Prediction of Sepsis Incidence in Critically Ill Patients Using Specific Genetic Polymorphisms. Biochem Genet. 2017;55:193-203. doi: 10.1007/s10528-016-9785-2.

10. Kloppenborg RP, Nederkoorn PJ, van der Graaf Y, Geerlings MI. Homocysteine and cerebral small vessel disease in patients with symptomatic atherosclerotic disease. The SMARTMR study. Atherosclerosis. 2011;216:461-466. doi: 10.1016/j. atherosclerosis.2011.02.027.

11. Bedreag $\mathrm{OH}$, Rogobete $\mathrm{AF}$, Sandesc D, et al. The Effects of Homocysteine Level in the Critically Ill Patient. A Review. Journal of Interdisciplinary Medicine. 2016;1:131-136. doi: 10.1515/jim-2016-0025.

12. Li H, Horke S, Förstermann U. Vascular oxidative stress, nitric oxide and atherosclerosis. Atherosclerosis. 2014;237:208-219. doi: 10.1016/j.atherosclerosis.2014.09.001.

13. Bedreag $\mathrm{OH}$, Rogobete $\mathrm{AF}$, Cradigati $\mathrm{CA}$, et al. A novel evaluation of microvascular damage in critically ill polytrauma patients by using circulating microRNAs. Romanian Journal of Laboratory Medicine. 2016;24:21-30. doi: 10.1515/rrlm-20160015 .

14. Gareus R, Kotsaki E, Xanthoulea S, et al. Article Endothelial Cell-Specific NF- $\mathrm{k}$ B Inhibition Protects Mice from Atherosclerosis. Cell Metab. 2008;8:372-383. doi: 10.1016/j. cmet.2008.08.016.

15. Papurica M, Rogobete AF, Sandesc D, et al. The Expression of Nuclear Transcription Factor Kappa B $(\mathrm{NF}-\kappa \mathrm{B})$ in the Case of Critically Ill Polytrauma Patients with Sepsis and Its Interactions with microRNAs. Biochem Genet. 2016;54:337347. doi: 10.1007/s10528-016-9727-z.

16. Bedreag $\mathrm{OH}$, Rogobete $\mathrm{AF}$, Sărăndan $\mathrm{M}$, et al. Oxidative stress and antioxidant therapy in traumatic spinal cord injuries. Rom J Anaesth Intensive Care. 2014;21:123-129.

17. Bedreag $\mathrm{OH}$, Rogobete $\mathrm{AF}$, Sarandan $\mathrm{M}$, et al. Oxidative stress in severe pulmonary trauma in critical ill patients. Antioxidant therapy in patients with multiple trauma - a review. Anaesthesiol Intensive Ther. 2015;47:351-359. doi: 10.5603/ AIT.a2015.0030.

18. Bedreag $\mathrm{OH}$, Sandesc $\mathrm{D}$, Chiriac SD, et al. The Use of Circulating miRNAs as Biomarkers for Oxidative Stress in Critically Ill Polytrauma Patients. Clin Lab. 2016;62:263-274. doi: 10.7754/ Clin.Lab.2015.150740. 
19. Papurica M, Rogobete AF, Sandesc D, et al. Advances in biomarkers in critical ill polytrauma patients. Clin Lab. 2016;62:977-986. doi: 10.7754/Clin.Lab.2015.151103.

20. Horhat FG, Gundogdu F, David LV, et al. Early Evaluation and Monitoring of Critical Patients with Acute Respiratory Distress Syndrome (ARDS) Using Specific Genetic Polymorphisms. 2017;55:204-211. doi: 10.1007/s10528-016-9787-0.

21. Papurica M, Rogobete AF, Sandesc D, et al. Redox Changes Induced by General Anesthesia in Critically Ill Patients with Multiple Traumas. Mol Biol Int. 2015;2015:238586. doi: 10.1155/2015/238586.

22. Dumache $\mathrm{R}$, Rogobete $\mathrm{AF}$, Bedreag $\mathrm{OH}$, et al. Use of miRNAs as Biomarkers in Sepsis. Anal Cell Pathol (Amst). 2015;2015:186716. doi: 10.1155/2015/186716.

23. Sandesc M, Rogobete AF, Bedreag $\mathrm{OH}$, et al. Analysis of oxidative stress-related markers in critically ill polytrauma patients: An observational prospective single-center study. Bosn J Basic Med Sci. 2018;18:191-197. doi: 10.17305/ bjbms.2018.2306.

24. Magenta A, Cencioni C, Fasanaro P, et al. miR-200c is upregulated by oxidative stress and induces endothelial cell apoptosis and senescence via ZEB1 inhibition. Cell Death Differ. 2011;18:1628-1639. doi: 10.1038/cdd.2011.42.

25. Zaccagnini G, Martelli F, Fasanaro P, et al. p66 ShcA Modulates Tissue Response to Hindlimb Ischemia. Circulation. 2004;109:2917-2923. doi: 10.1161/01. CIR.0000129309.58874.0F.

26. Lin $Y$, Liu $X$, Cheng $Y$, et al. Involvement of MicroRNAs in Hydrogen Peroxide-mediated Gene Regulation and Cellular Injury Response in Vascular Smooth Muscle Cells. J Biol Chem. 2009;284:7903-7913. doi: 10.1074/jbc.M806920200.

27. Cybulsky MI, Iiyama $\mathrm{K}$, Li H, et al. A major role for VCAM1, but not ICAM-1, in early atherosclerosis. J Clin Invest. 2001;107:1209-1210. doi: 10.1172/JCI11871.

28. Lu J, Liu F, Liu D, et al. Amlodipine and atorvastatin improved hypertensive cardiac hypertrophy through regulation of receptor activator of nuclear factor kappa $\mathrm{B}$ ligand/receptor activator of nuclear factor kappa B/osteoprotegerin system in spontaneous hypertension rats. Exp Biol Med. 2016;241:12371249. doi: 10.1177/1535370216630180.

29. Bendaya I, Riahi A, Kharat M, et al. STAT1 and STAT6 Act as Antagonistic Regulators of PPAR $\gamma$ in Diabetic Patients with and without Cardiovascular Diseases. Clin Lab. 2018;64:287294. doi: 10.7754/Clin.Lab.2017.171013.

30. Fehlmann T, Meese E, Keller A. Exploring ncRNAs in Alzheimer's disease by miRMaster. Oncotarget. 2017;8:37713772. doi: 10.18632/oncotarget.14054.

31. Bedreag $\mathrm{OH}$, Rogobete AF, Sandesc D, et al. Modulation of the Redox Expression and Inflammation Response in the Crtically Ill Polytrauma Patient with Thoracic Injury. Statistical Correlations between Antioxidant Therapy and Clinical Aspects. A Retrospective Single Center Study. Clin Lab. 2016;62:1747-1759. doi: 10.7754/Clin.Lab.2016.160206.

32. Bratu LM, Rogobete AF, Papurica M, et al. Literature Research Regarding miRNAs' Expression in the Assessment and Evaluation of the Critically Ill Polytrauma Patient with Traumatic Brain and Spinal Cord Injury. Clin Lab. 2016;62:2019-2024. doi: 10.7754/Clin.Lab.2016.160327.

33. Dumache R, Ciocan V, Muresan C, Enache A. Molecular DNA Analysis in Forensic Identification. Clin Lab. 2016;62:245248. doi: 10.7754/Clin.Lab.2015.150414.
34. Cannino G, Di Liegro CM, Rinaldi AM. Nuclear-mitochondrial interaction. Mitochondrion. 2007;7:359-366. doi: 10.1016/j. mito.2007.07.001.

35. Karginov FV, Conaco C, Xuan Z, et al. A biochemical approach to identifying microRNA targets. Proc Natl Acad Sci U S A. 2007;104:19291-19296. doi: 10.1073/pnas.0709971104.

36. Yang Z, Cappello T, Wang L. Emerging role of microRNAs in lipid metabolism. Acta Pharm Sin B. 2015;5:145-150. doi: 10.1016/j.apsb.2015.01.002.

37. Pirtea L, Grigoraş D, Matusz P, et al. Human Papilloma Virus Persistence after Cone Excision in Women with Cervical High Grade Squamous Intraepithelial Lesion: A Prospective Study. Can J Infect Dis Med Microbiol. 2016;2016:3076380. doi: 10.1155/2016/3076380.

38. Pirtea L, Grigoraş D, Matusz P, et al. Age and HPV type as risk factors for HPV persistence after loop excision in patients with high grade cervical lesions: an observational study. BMC Surg. 2016;16:1-7. doi: 10.1186/s12893-016-0185-7.

39. Pirtea L, Raica M, Cimpean AM (2012) Endothelial cell activation and proliferation in ovarian tumors: Two distinct steps as potential markers for antiangiogenic therapy response. Mol Med Rep. 2012;5:1181-1184. doi: 10.3892/ mmr.2012.812.

40. Zhang X, Azhar G, Wei JY. The Expression of microRNA and microRNA Clusters in the Aging Heart. PLoS One. 2012;7:1-13. doi: 10.1371/journal.pone.0034688.

41. Dumache R, Ciocan V, Muresan C, et al. Circulating microRNAs as promising biomarkers in forensic body fluids identification. Clin Lab. 2015;61:1129-1135. doi: 10.7754/Clin.Lab.2015.150207.

42. Dumache R, Muresan C, Ciocan V, et al. Post-Mortem Identification of a Fire Carbonized Body by STR Genotyping. Clin Lab. 2016;62:2033-2037. doi: 10.7754/Clin.Lab.2016.160417.

43. Ticlea M, Melania L, Bodog F, Horea O. The Use of Exosomes as Biomarkers for Evaluating and Monitoring Critically Ill Polytrauma Patients with Sepsis. Biochem Genet. 2017;55:1-9. doi: 10.1007/s10528-016-9773-6.

44. Nitu R, Florin A, Gundogdu F, et al. microRNAs Expression as Novel Genetic Biomarker for Early Prediction and Continuous Monitoring in Pulmonary Cancer. Biochem Genet. 2017;55:281290. doi: 10.1007/s10528-016-9789-y.

45. Rogobete AF, Bedreag OH, Popovici SE, et al. Detection of Myocardial Injury Using miRNAs Expression as Genetic Biomarkers in Acute Cardiac Care. Journal of Cardiovascular Emergencies. 2016;2:169-172 . doi: 10.1515/jce-2016-0025.

46. Papurica M, Rogobete AF, Sandesc D, et al. Using the Expression of Damage-Associated Molecular Pattern (DAMP) for the Evaluation and Monitoring of the Critically Ill Polytrauma Patient. Clin Lab. 2016;62:1829-1840. doi: 10.7754/Clin.Lab.2016.160226.

47. Sandesc M, Dinu A, Rogobete AF, et al. Circulating microRNAs expressions as genetic biomarkers in pancreatic cancer patients continuous non-invasive monitoring. Clin Lab. 2017;63:1561-1566. doi: 10.7754/Clin.Lab.2017.170608.

48. Negoita SI, Sandesc D, Rogobete AF, et al (2017) MiRNAs expressions and interaction with biological systems in patients with Alzheimer's disease. Using miRNAs as a diagnosis and prognosis biomarker. Clin Lab. 2017;63:1315-1321. doi: 10.7754/Clin.Lab.2017.170327.

49. Bratu LM, Rogobete AF, Papurica $M$, et al. Literature Research Regarding miRNAs' Expression in the Assessment and Evaluation of the Critically Ill Polytrauma Patient 
with Traumatic Brain and Spinal Cord Injury. Clin Lab. 2016;62:2019-2024. doi: 10.7754/Clin.Lab.2016.160327.

50. Bedreag OH, Sandesc D, Chiriac SD, et al. The Use of Circulating miRNAs as Biomarkers for Oxidative Stress in Critically Ill Polytrauma Patients. Clin Lab. 2016;62:263-274.doi: 10.7754/ Clin.Lab.2015.150740.

51. McCall CE, El Gazzar M, Liu T, Vachharajani V, Yoza B. Epigenetics, bioenergetics, and microRNA coordinate genespecific reprogramming during acute systemic inflammation. J Leukoc Biol. 2011;90:439-46. doi: 10.1189/jlb.0211075.

52. Olivieri F, Rippo MR, Prattichizzo F, et al. Toll like receptor signaling in "inflammaging": microRNA as new players. Immun Ageing. 2013;10:11. doi: 10.1186/1742-4933-10-11.

53. Ucar A, Gupta SK, Fiedler J, et al. The miRNA-212/132 family regulates both cardiac hypertrophy and cardiomyocyte autophagy. Nat Commun. 2012;3:1078. doi: 10.1038/ ncomms2090.

54. Long G, Wang F, Duan Q, et al. Human Circulating MicroRNA-1 and MicroRNA-126 as Potential Novel Indicators for Acute Myocardial Infarction. Int J Biol Sci. 2012;8:811-888. doi: 10.7150/ijbs.4439.

55. Greco S, Gorospe M, Martelli F. Noncoding RNA in age-related cardiovascular diseases. J Mol Cell Cardiol. 2015;83:142-155. doi: 10.1016/j.yjmcc.2015.01.011.

56. Fichtlscherer S, Rosa S De, Fox H, et al. Circulating MicroRNAs in Patients With Coronary Artery Disease. Circ Res. 2010;107:677-684. doi: 10.1161/CIRCRESAHA.109.215566.

57. Romaine SPR, Tomaszewski M, Condorelli G, Samani NJ. MicroRNAs in cardiovascular disease: An introduction for clinicians. Heart. 2015;101:921-928. doi: 10.1136/ heartjnl-2013-305402.

58. Cheng Y, Tan N, Yang J, et al. A translational study of circulating cell-free microRNA-1 in acute myocardial infarction. 2010;95:87-95. doi: 10.1042/CS20090645.

59. Gidlöf O, Andersson P, Pals J Van Der, et al. Cardiospecific microRNA Plasma Levels Correlate with Troponin and Cardiac Function in Patients with ST Elevation Myocardial Infarction , Are Selectively Dependent on Renal Elimination, and Can Be Detected in Urine Samples. Cardiology. 2011;118:217-226. doi: 10.1159/000328869.

60. Wang R, Li N, Zhang Y, et al. Circulating MicroRNAs are Promising Novel Biomarkers of Acute Myocardial Infarction. Intern Med. 2011;50:1789-1795. doi: 10.2169/ internalmedicine.50.5129.

61. Alessandra YD, Carena MC, Spazzafumo L, et al. Diagnostic Potential of Plasmatic MicroRNA Signatures in Stable and Unstable Angina. PLoS One. 2013;8:e80345. doi: 10.1371/ journal.pone.0080345.

62. Hoekstra M, van der Lans CAC, Halvorsen B, et al. The peripheral blood mononuclear cell microRNA signature of coronary artery disease. Biochem Biophys Res Commun. 2010;394:792797. doi: https://doi.org/10.1016/j.bbrc.2010.03.075.
63. Tijsen AJ, Creemers EE, Moerland PD, et al. MiR423$5 \mathrm{p}$ as a circulating biomarker for heart failure. Circ Res. 2010;106:1035-1039. doi: 10.1161/CIRCRESAHA.110.218297.

64. Caporali A, Meloni M, Vo C, et al. Deregulation of microRNA-503 Contributes to Diabetes Mellitus-Induced Impairment of Endothelial Function and Reparative Angiogenesis After Limb Ischemia. Circulation. 2011;123:282-291. doi: 10.1161/ CIRCULATIONAHA.110.952325.

65. Liu C, Liu N, Cao B, et al. CircRNAs as Potential Biomarkers in Gastrointestinal Tract Tumors : Opportunities and Challenges. Clin Lab. 2018;64:141-145. doi: 10.7754/Clin.Lab.2017.170731.

66. Giden R, Gökdemir MT, Erel Ö, et al. The Relationship Between Serum Thiol Levels and Thiol/Disulfide Homeostasis with Head Trauma in Children. Clin Lab. 2018;64:163-168. doi: 10.7754/Clin.Lab.2017.170816.

67. Ma X, Buscaglia LEB, Barker JR, Li Y. MicroRNAs in NF- k B signaling. J Mol Cell Biol. 2011;3:159-166. doi: 10.1093/jmcb/ mjroo7.

68. Oeckinghaus A, Ghosh S. The NF- k B Family of Transcription Factors and Its Regulation. Cold Spring Harb Perspect Biol. 2009;1:a000034. doi: 10.1101/cshperspect.a000034.

69. Zhang H, Sun SC. NF- $\mathrm{KB}$ in inflammation and renal diseases. Cell Biosci. 2015;5:63. doi: 10.1186/s13578-015-0056-4.

70. Kleniewska P, Piechota-polanczyk A, Michalski L, et al. Influence of Block of NF-Kappa B Signaling Pathway on Oxidative Stress in the Liver Homogenates. Oxid Med Cell Longev. 2013;2013:308358. doi: 10.1155/2013/308358.

71. Hajra L, Evans AI, Chen M, et al. The NF- $\mathrm{\kappa B}$ signal transduction pathway in aortic endothelial cells is primed for activation in regions predisposed to atherosclerotic lesion formation. Proc Natl Acad Sci U S A. 2000;97:9052-9057.

72. Kanters E, Pasparakis M, Gijbels MJJ, et al. Inhibition of NF$\kappa \mathrm{B}$ activation in macrophages increases atherosclerosis in LDL receptor-deficient mice. J Clin Invest. 2003;112:1176-1185. doi: 10.1172/JCI18580.

73. Yurdagul A, Sulzmaier FJ, Chen XL, et al. Oxidized LDL induces FAK-dependent RSK signaling to drive NF- $\kappa \mathrm{B}$ activation and VCAM-1 expression. J Cell Sci. 2016;129:1580-1591. doi: 10.1242/jcs.182097.

74. Meng Y, Chen C, Liu Y, et al. Angiotensin II Regulates Dendritic Cells through Activation of NF- $\mathrm{kB} / \mathrm{p} 65$, ERK1/2 and STAT1 Pathways. Cell Physiol Biochem. 2017;42:1550-1558. doi: 10.1159/000479272.

75. Wang H, Wei Y, Zeng Y, et al. The association of polymorphisms of TLR4 and CD14 genes with susceptibility to sepsis in a Chinese population. BMC Med Genet. 2014;15:123. doi: 10.1186/ S12881-014-0123-4.

76. Ye E, Steinle JJ. miR-146a Attenuates Inflammatory Pathways Mediated by TLR4/NF- $\mathrm{BB}$ and TNF- $\alpha$ to Protect Primary Human Retinal Microvascular Endothelial Cells Grown in High Glucose. Mediators of Inflammation. 2016;2016:3958453. https://doi.org/10.1155/2016/3958453. 